\title{
Pelvic floor muscle training protocol for stress urinary incontinence in women: A systematic review
}

\author{
Marlene Oliveira $^{1}$, Margarida Ferreira ${ }^{2 *}$, Maria João Azevedo ${ }^{3}$, João Firmino-Machado ${ }^{4}$, Paula Clara Santos ${ }^{5,6}$ \\ ${ }^{1}$ Physiotherapist, Camélia Hotel Sénior \& Homes, Guimarães, Portugal \\ ${ }^{2}$ Visiting Professor, Physiotherapy Department, CESPU - Instituto Politécnico de Saúde do Norte, Vale do Sousa e Vale do Ave, Portugal \\ ${ }^{3} \mathrm{MD}$, Assistant Physiatrist, Hospital Senhora da Oliveira, Guimarães, Portugal \\ ${ }^{4} \mathrm{MD}$, Department of Public Health, Porto, Portugal \\ 5Lecturer, Department of Physiotherapy, Escola Superior de Tecnologia e Saúde do Porto, Instituto Politécnico do Porto, Porto, Portugal \\ ${ }^{6}$ Research Centre in Physical Activity, Health and Leisure, Faculty of Sport, Universidade do Porto, Porto, Portugal
}

Study conducted at the Department of Physiotherapy, Instituto Politécnico do Porto, Porto, Portugal

Article received: $12 / 12 / 2016$ Accepted for publication: $3 / 1 / 2017$

*Correspondence:

Departamento de Fisioterapia,

Instituto Politécnico do Porto

Address: Rua Dr. António Bernardino

de Almeida, 400

Porto - Portugal

Postal code: 4200-072

margasufer@gmail.com

http://dx.doi.org/10.1590/1806-9282.63.07.642

\section{SUMmARY}

Introduction: Strengthening exercises for pelvic floor muscles (SEPFM) are considered the first approach in the treatment of stress urinary incontinence (SUI). Nevertheless, there is no evidence about training parameters.

Objective: To identify the protocol and/or most effective training parameters in the treatment of female SUI.

Method: A literature research was conducted in the PubMed, Cochrane Library, PEDro, Web of Science and Lilacs databases, with publishing dates ranging from January 1992 to March 2014. The articles included consisted of English-speaking experimental studies in which SEPFM were compared with placebo treatment (usual or untreated). The sample had a diagnosis of SUI and their age ranged between 18 and 65 years. The assessment of methodological quality was performed based on the PEDro scale. Results: Seven high methodological quality articles were included in this review. The sample consisted of 331 women, mean age $44.4 \pm 5.51$ years, average duration of urinary loss of $64 \pm 5.66$ months and severity of SUI ranging from mild to severe. SEPFM programs included different training parameters concerning the PFM. Some studies have applied abdominal training and adjuvant techniques. Urine leakage cure rates varied from 28.6 to $80 \%$, while the strength increase of PFM varied from 15.6 to $161.7 \%$. Conclusion: The most effective training protocol consists of SEPFM by digital palpation combined with biofeedback monitoring and vaginal cones, including 12 week training parameters, and ten repetitions per series in different positions compared with SEPFM alone or a lack of treatment.

Keywords: training, pelvic floor, urinary stress incontinence, women.

\section{INTRODUCTION}

The International Continence Society (ICS) and the International Urogynecological Association define urinary incontinence (UI) as a symptom, namely "the complaint of any involuntary loss of urine." ${ }^{1} \mathrm{UI}$ is classified according to the record of signs, symptoms and results from urodynamic study (UDS). ${ }^{1}$ Stress urinary incontinence (SUI) is "the complaint of involuntary urine loss on effort or physical exertion, or on sneezing or coughing."1

Worldwide, SUI is predominant in females, and the mean prevalence in the various studies is $25 \% .^{2,3}$ It can, however, range from $10 \%$ in young women ${ }^{3}$ to $45 \%$ among the elderly. ${ }^{3}$
UI has a devastating effect on women's quality of life in the physical, social, sexual and psychological spheres. ${ }^{4}$ Women restrict or diminish their activity and social participation, with serious implications. ${ }^{5}$

In SUI, there is an association between physical exertion and urinary loss. ${ }^{6}$ Increased intra-abdominal pressure triggered by physical exertion leads to increased intravesical pressure and, if it exceeds intraurethral pressure, in the absence of contraction of the detrusor muscle, the resulting urinary leakage is referred to as SUI. ${ }^{6-8}$ The pathophysiology underlying this condition follows two mechanisms: hypermobility of the urethra and bladder neck, and intrinsic deficiency of the urethral sphincter. ${ }^{7-9}$ 
The recommendations of the Agency for Health Care Policy and Research suggest that the first intervention in the treatment of SUI should be conservative. Pelvic floor rehabilitation includes behavioral modifications and advice on everyday life hygiene, intravaginal manual reeducation, strengthening exercises for pelvic floor muscles (SEPFM), electrical stimulation, biofeedback and vaginal cones. ${ }^{10}$ Rehabilitation of pelvic floor muscles (PFM) may be active and/or passive, but reeducation depends on a request of voluntary muscle contraction. Active exercises include SEPFM, intravaginal manual reeducation, vaginal cones and biofeedback, while passive exercise refers to electrical stimulation. ${ }^{10}$ Investigations ${ }^{11-13}$ demonstrated similar effectiveness of different SEPFM programs, but no evidence of a specific, standardized program. These investigations differ regarding the parameters used in the training programs: eight ${ }^{14-16}$ to forty repetitions $;{ }^{17} \mathrm{two}^{15}$ to five series; ${ }^{16}$ submaximal ${ }^{14,18}$ to maximum contractions; ; ${ }^{15,16}$ duration of five weeks ${ }^{16}$ to six months; $;{ }^{14}$ three times a week ${ }^{14}$ to daily; ${ }^{19}$ instruction on muscle contraction using digital palpation; ${ }^{18}$ biofeedback ${ }^{19}$ or perineal ultrasound; ${ }^{20}$ individual ${ }^{20}$ or group sessions:; ${ }^{21}$ supervised training ${ }^{14}$ or home practice. ${ }^{10,19,22}$ In general, SEPFM is effective in the treatment of female SUI; however, there is a great heterogeneity of programs, not allowing identification of the most effective protocol.

The objective of our review was to identify the most effective protocol and/or PFM training parameters to treat female SUI.

\section{Method}

The structural and content organization of our systematic review was based on the recommendations of the PRISMA statement. ${ }^{23,24}$

Eligible studies were of an experimental nature comparing SEPFM to placebo, usual treatment or lack of treatment. They presented high methodological expressiveness (score $\geq 5$ on the PEDro scale) and were written in English.

The participants were female, aged between 18 and 65 years, diagnosed with SUI based on subjective perception (symptom) and/or clinical evaluation (signal) and/or UDS (uroflowmetry and cystometry). Exclusion criteria included diagnosis of SUI triggered by factors external to the lower urinary tract (neurological pathologies, cognitive deficits), pregnant and postpartum women, $\geq$ stage 2 prolapse in the Pelvic Organ Prolapse Quantification (POP-Q), and other types of UI (mixed and urgent).

\section{Search strategy}

The search covered five databases: PubMed (Medline), Cochrane Library, PEDro, Web of Science and Lilacs. In addition, we conducted a manual survey from the bibliography of the articles, systematic reviews and meta-analyses included, as well as on the ICS website, in order to reduce publication bias. ${ }^{25}$ Studies included were published between January 1992 and March 2014. The Medical Subject Headings (MeSH) of the National Library of Medicine enabled the identification and the combination of keywords pertaining to: the pathology (urinary stress incontinence), interventions (pelvic floor muscle training; pelvic floor muscle exercise; physical therapy; program; protocol; rehabilitation), population (women; female), and study design (randomized controlled trial; controlled clinical trial; comparative study; research design).

The final search choice included the following keywords: (pelvic floor muscle) AND ("education" OR "training" OR "education" [MeSH Terms] OR "training") OR (pelvic floor muscle exercise) AND physical therapy OR physiotherapy OR protocol OR program OR rehabilitation AND (stress urinary incontinence) AND women AND female AND (randomized controlled trial OR controlled clinical trial OR comparative study OR research design) NOT (pregnancy $\mathrm{OR}$ animals).

\section{Methodological quality}

The methodological quality of the studies was analyzed by three independent researchers using the PEDro scale. This assessment tool has 11 items, with a maximum score of 10 points. ${ }^{26}$ For each criterion presented in the scale (except for the first one), a score of 1 or 0 points can be attributed. ${ }^{26}$ The PEDro scale was created by Moseley et al. in 1999 based on the Delphi List, and was translated and adapted for the Portuguese population by Costa in 2011 .

\section{RESULTS}

\section{Search strategy results}

The search in the databases led to the identification of 591 potentially relevant studies (Figure 1).

\section{Methodological quality results}

The mean score for methodological quality evaluation was $5.7 \pm 1.28(\mathrm{~min} / \mathrm{max}: 5 / 8)$ out of 10 points (Table 1$)$.

The items that most contributed for the decrease of the total score were the 5 (blind study regarding the participants) and 6 (blind study regarding therapists) (Table 1).

\section{Description of the studies}

Our systematic review identified seven experimental studies. The studies were conducted between 1996 and 2013, with a total sample of 331 women. 


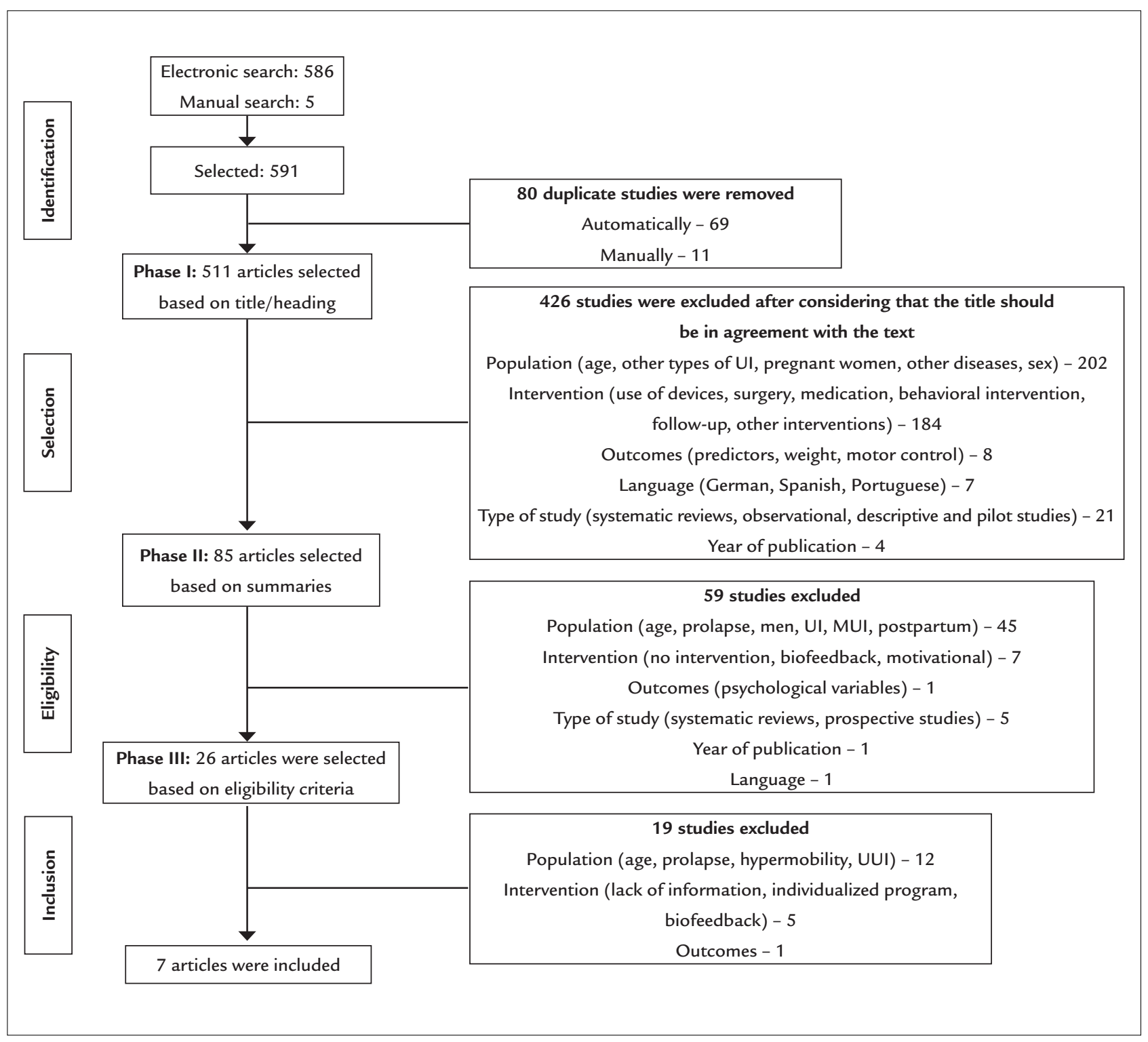

FIGURE 1 Study selection flowchart.

\section{TABLE 1 Classification of the methodological quality of studies according to the PEDro scale.}

\begin{tabular}{|c|c|c|c|c|c|c|c|c|c|c|c|c|}
\hline Studies & 1 & 2 & 3 & 4 & 5 & 6 & 7 & 8 & 9 & 10 & 11 & Total \\
\hline Glavind et al. ${ }^{30}$ & 1 & 1 & 1 & 1 & 0 & 0 & 0 & 1 & 0 & 1 & 1 & 6 \\
\hline Arvonen et al. ${ }^{29}$ & 1 & 1 & 0 & 1 & 0 & 0 & 0 & 1 & 0 & 1 & 1 & 5 \\
\hline Aksac et al. ${ }^{19}$ & 1 & 1 & 1 & 1 & 0 & 0 & 0 & 0 & 1 & 1 & 0 & 5 \\
\hline Zanetti et al. ${ }^{18}$ & 1 & 1 & 1 & 1 & 0 & 0 & 0 & 1 & 0 & 1 & 1 & 6 \\
\hline Felicíssimo et al. ${ }^{31}$ & 1 & 1 & 1 & 0 & 0 & 0 & 0 & 1 & 0 & 1 & 1 & 5 \\
\hline Sriboonreung et al. ${ }^{28}$ & 1 & 1 & 1 & 1 & 0 & 0 & 0 & 1 & 0 & 1 & 0 & 5 \\
\hline Kamel t al. ${ }^{27}$ & 1 & 1 & 1 & 1 & 0 & 0 & 1 & 1 & 1 & 1 & 1 & 8 \\
\hline
\end{tabular}




\section{Characteristics of the studies}

Sample size varied between $30^{27}$ and $68^{28}$ women, with a mean age of $48.8 \pm 5.51$ years, ranging from 25 to 65 years..$^{27-30}$ The mean duration of urine loss was $64 \pm 5.66$ months ${ }^{18,29,31}$ with severity ranging from mild ${ }^{19,27}$ to severe (even though the definition of the severity of UI is not expressed). ${ }^{30}$

The diagnosis of SUI was demonstrated through subjective evaluation/symptoms (questionnaire, interview), ${ }^{19,27,29,31}$ physical examination/signs (pad test, gynecological evaluation) ${ }^{19,27-31}$ and/or UDS. ${ }^{18,19,27,31}$

\section{Interventions}

In most studies, the program began with instructions for contracting PFM. Methods most often used were digital palpation ${ }^{19,27,31}$ and teaching of the anatomy and function of PFM. ${ }^{29-31}$ Only one study used biofeedback, ${ }^{19}$ while two omitted the teaching of contraction. ${ }^{18,28}$

Two studies combined SEPFM and biofeedback, ${ }^{19,30}$ one combined the exercises with vaginal cones, ${ }^{29}$ two compared SEPFM supervised or not, ${ }^{18,30}$ and other two compared the exercises with and without the activation of abdominal muscles. ${ }^{27,28}$ SEPFM program parameters included length of contractions, which ranged from $1 \mathrm{~s}^{28}$ to $20 \mathrm{~s}^{29}$, length of rest from $1 \mathrm{~s}^{18}$ to $20 \mathrm{~s}^{19,27}$ and number of series, ranging from $2^{27}$ to $40 .^{19}$

Three studies used maximum contractions ${ }^{27,28,31}$ and two applied a combination of submaximal and maximum contractions. ${ }^{18,29}$ As for training positions, the one most often used was supine, ${ }^{18,19,27,30,31}$ followed by standing, ${ }^{18,29-31}$ seated $^{18,29-31}$ and lateral decubitus position. ${ }^{31}$ Two studies, however, did not specify a training position. ${ }^{19,28}$

Regarding the frequency of sessions, the minimum applied was two sessions per week, ${ }^{30}$ while daily treatment was the most frequent. ${ }^{18,19,28,29,31}$

The analyzed programs lasted between $8^{19,31}$ and 16 weeks, ${ }^{29}$ and most opted for a 12 -week duration. ${ }^{18,27,28,30}$

\section{Instruments used to measure outcomes}

Almost all of the studies ( 6 out of 7 ) assessed the amount of urine leakage based on 1-hour and 24-hour pad tests. ${ }^{18,19,28-31}$ PFM strength was assessed by digital palpation ${ }^{19,29,31}$ and

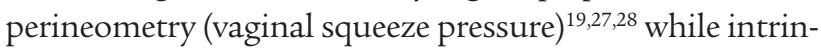
sic sphincter was assessed by UDS. ${ }^{27}$ Other outcomes included a subjective assessment based on a visual analogue scale, ${ }^{19}$ quality of life scales (QV-I-QOL, QV-ICIQ-SF) ${ }^{18,31}$ and voiding diaries. ${ }^{18}$

\section{Cure rate results}

Six studies ${ }^{18,19,28-31}$ displayed their assessments of cure rates measured by pad test ranging between $<1 \mathrm{~g}^{19,30}$ and $<2$ g. ${ }^{18,29,31}$
The results of cure rate according to the type of intervention were: 50\% (cones) versus 26\% (PFM Training - PFMT); ${ }^{29}$ $36.6 \%$ (supervised PFMT) versus 34.5\% (unsupervised); $; 1$ $58 \%$ (PFMT+biofeedback) versus 20\% (PFMT); ${ }^{30} 48 \%$ (PFMT+supervision) versus $9.5 \%$ (unsupervised) $;{ }^{18} 75 \%$ (PFMT+palpation) versus 80\% (PFMT+biofeedback) versus $0 \%$ (no treatment). ${ }^{19}$ For intervention periodicity, cure rates were $28.6 \%$ (daily PFMT) versus $21.2 \%$ (PFMT three times weekly) versus 20\% (abdominal training) ${ }^{28}$ (Table 2).

On perineometry, PFM strength increased to $84.7 \%$ (PFMT+palpation) versus 161.7\% (PFMT+biofeedback) versus $7 \%$ (no treatment); ${ }^{19}$ 15.6\% (SEPFM) versus $4.7 \%$ (abdominal muscle strength) ${ }^{27}$ and 63.4\% (daily) versus 48.4\% (three times weekly) versus 59.7\% (SEPFM+abdominal, three times weekly). ${ }^{28}$ On digital palpation, PFM strength reached $37.5 \%$ (digital palpation) versus $48.9 \%$ (biofeedback) versus $0 \%$ (no treatment); ${ }^{19} 33 \%$ (SEPFM) versus $0 \%$ (vaginal cones); ${ }^{29}$ and 50\% (supervised) versus 50\% (unsupervised). ${ }^{31}$ On UDS, intraurethral pressure increased 16\% (abdominal muscle strength) versus 9.1\% (SEPFM) ${ }^{27}$ (Table 2).

Subjective perception of cure increased from $23.8^{18}$ to $75 \% .^{28}$

\section{Discussion}

Our systematic review confirmed the diversity in study designs, measurement instruments, cure rate definitions, and intervention outcomes.

Zanetti et al. ${ }^{18}$ found that supervised SEPFM were more effective than unsupervised SEPFM, unlike another study, ${ }^{31}$ which demonstrated the equal efficacy of both. The heterogeneity of the results may derive from the different manners of measuring the pad test (24-h and 1-h) and the duration of the interventions (8 and 12 weeks), respectively. ${ }^{18,31}$ The pad test is an instrument that reveals the amount of urinary leakage in grams, in addition to being inexpensive and non-invasive. ${ }^{32}$ According to Jørgensen et al., ${ }^{33}$ the correlation coefficient varies between 0.68 and $0.93 .{ }^{33}$ The investigations are inconsistent regarding pad test application duration (1-h or 24-h), although some guidelines recommend the long-duration pad test (24 hours) as it allows the reproduction of urine losses during daily activities according to an individual's bladder capacity, compared with the 1-hour pad test, which requires a standardized bladder volume and provokes urine leakage in distinct physical activities. ${ }^{32}$

In our review, combined therapy with SEPFM and abdominal muscle strengthening training significantly increased PFM strength, as proven by perineometry $(\mathrm{p}<0.05) \cdot{ }^{27,28}$ However, there were no statistically significant differences in reducing the amount of urine leakage. ${ }^{28}$ 


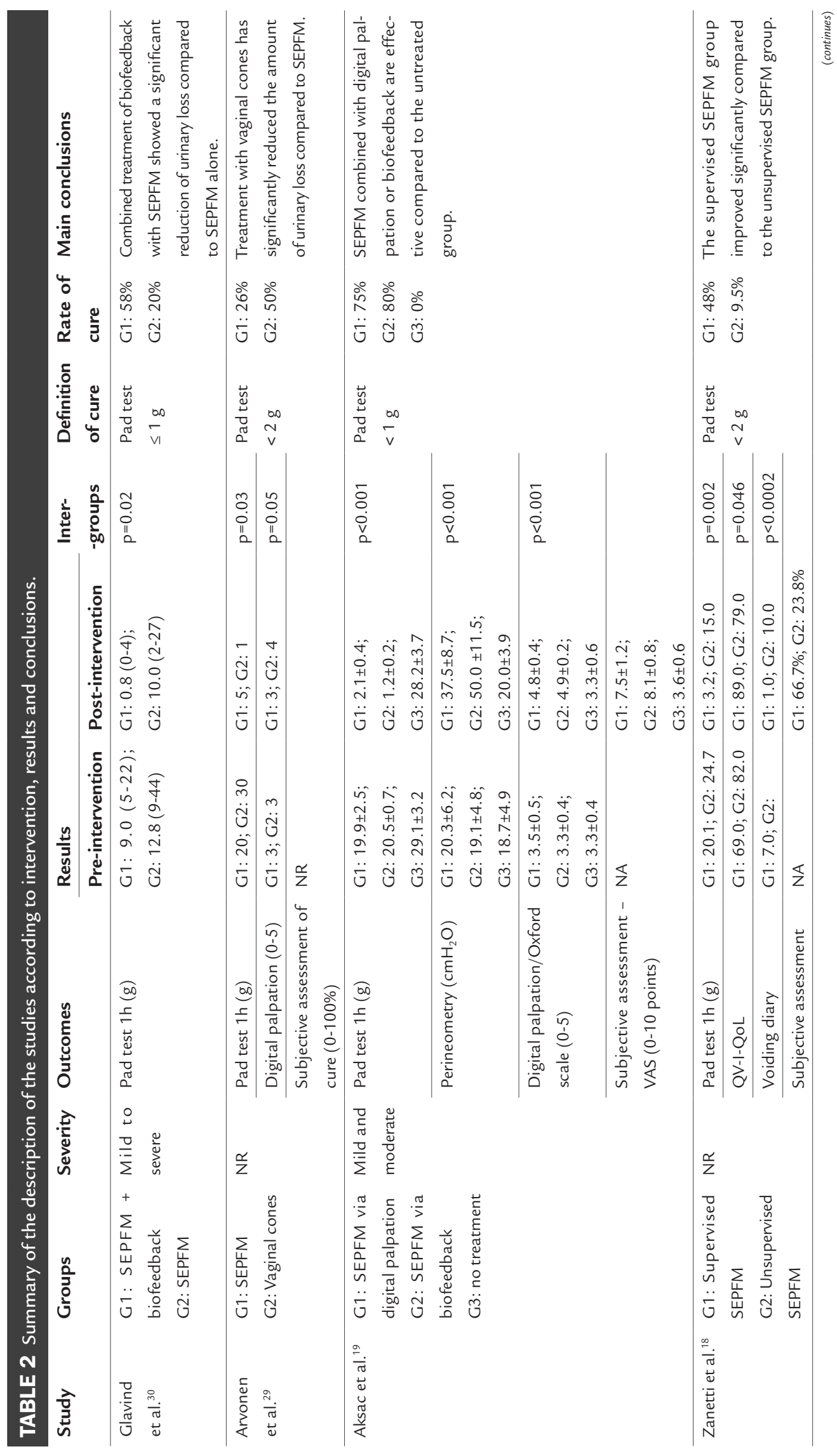




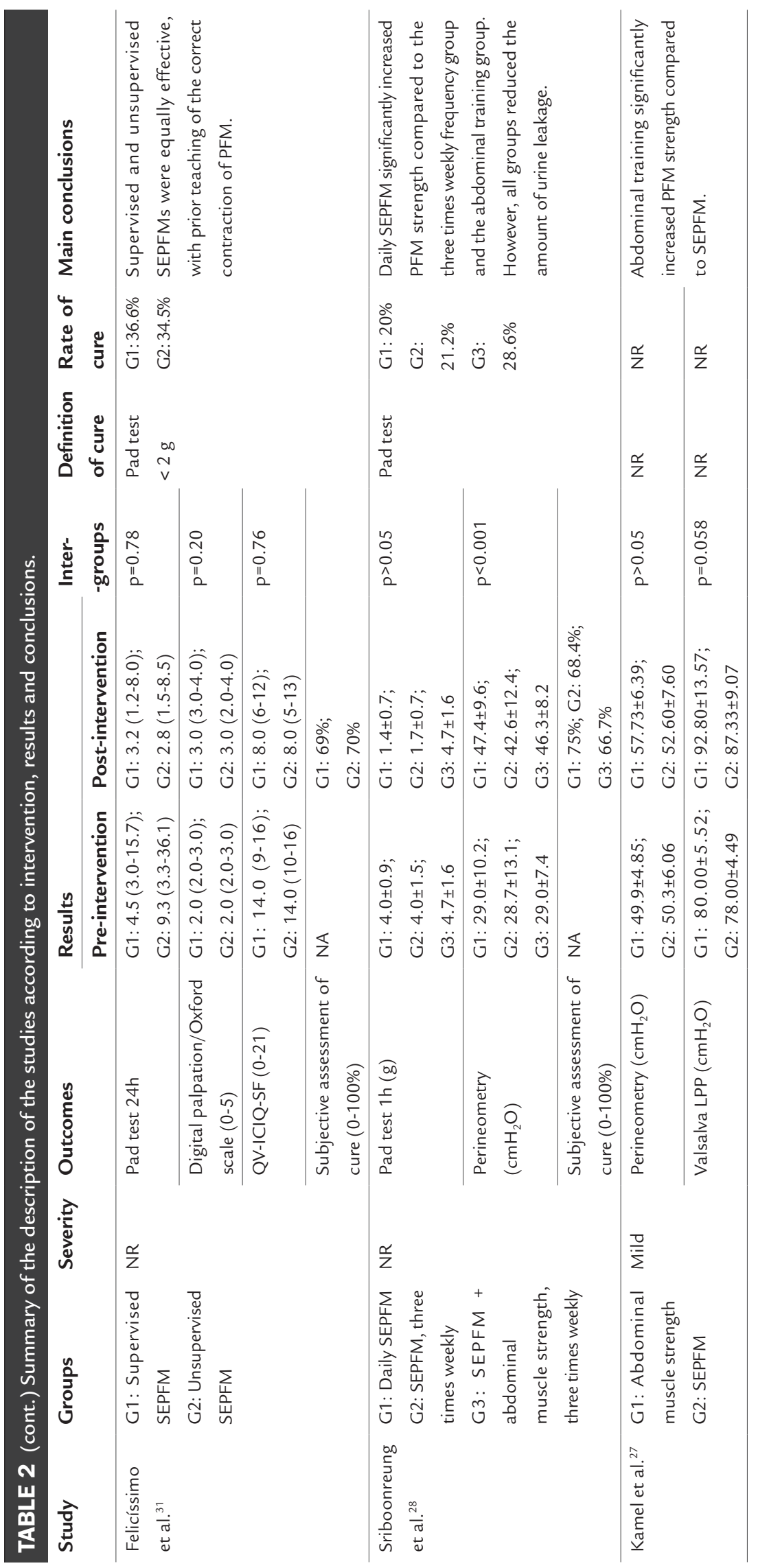


According to Sapsford et al. ${ }^{34}$ training of deep abdominal muscles triggers the co-contraction of PFM, causing an increase in the strength of PFM and an improvement in urinary continence. A systematic review by Kari Bø et al. ${ }^{35}$ concluded that the results are ambivalent because, to date, there is no strong clinical evidence of benefit with abdominal muscle training in women with UI.

In the studies included in the review, PFM training programs including adjuvant therapies such as biofeedback, digital palpation and vaginal cones reach high rates of cure (80, 50 and $58 \%$, respectively). ${ }^{19,27,31}$ A systematic review by Neumann et al. ${ }^{36}$ demonstrated that SEPFM combined with adjuvant therapies were effective in the treatment of SUI, reaching a cure rate of $73 \%$. These PFM strengthening techniques allow identification, awareness of correct muscle contraction, and inhibition of synergistic muscles, enhancing results. ${ }^{37}$

The PFM training programs differed in the following parameters: type of muscle contraction, number of repetitions and series, rest time between each contraction, time of contraction and progressivity of the exercises. Nevertheless, most of the studies that were analyzed showed consistency in the repetition frequency parameter (ten initial repetitions), except for the study by Kamel et al., ${ }^{27}$ who initiated the SEPFM program with 15 repetitions. This parameter corroborates the parameters of strength training to obtain muscular hypertrophy advocated by the American College of Sports Medicine, ${ }^{38,39}$ which recommends 8 to 12 contractions per series.

The frequency of SEPFM was predominantly intensive (one to three times per day), but the study by Sriboonreung et al..$^{28}$ failed to verify significant differences in reducing the amount of urine leakage by using different frequencies of SEPFM. The current evidence for the principles of strength training recommends that the frequency of three times weekly is sufficient for muscle hypertrophy. ${ }^{38,39}$

In most studies, ${ }^{18,27,28,30}$ the training program duration was 12 weeks, except for two studies ${ }^{19,31}$ that applied SEPFM for 8 weeks. According to the recommendations of the American College of Sports Medicine, strength training programs should last at least $15-20$ weeks. ${ }^{38} \mathrm{PFM}$ are skeletal muscles and, therefore, the recommendations of strength training are not different from other skeletal muscles. ${ }^{12}$ In the first 8 weeks of training, the changes are essentially neural (increased number and frequency of motor unit activation), followed by muscle hypertrophy due to increased volume and number of myofibrils, essential for morphological or structural adaptations. ${ }^{36}$ In our systematic review, training programs of 8 to 12 weeks seem to reduce the amount of urine leakage, and/or to increase PFM strength, inferring that short-term training is equally effective in the treatment of SUI. However, these results should be analyzed with caution, because the gain of muscular strength in this period was sustained by an increase in number and synchronism of the motor units, ${ }^{36}$ without any mention of patient follow-up after training, in addition to the fact that the studies included in the analysis used different designs, eligibility criteria and measuring instruments. Also, some of the studies ${ }^{28,29}$ in our review demonstrated that increasing the strength of PFM in this short period of time may not be related to a significant reduction in the amount of urine loss. This suggests that the increase in PFM strength and urethral resistance does not seem to guarantee the mechanism of urinary continence. ${ }^{28,29}$ According to some authors, coordination between early contraction of PFM and increased intra-abdominal pressure may be the most relevant factor in reducing urine leakage compared to the strength gain of PFM, which may justify the positive results of short training programs. ${ }^{7,40}$

We found in our review that five studies used different positions to perform the exercises, so that the most commonly applied ones were the standing, seated and lateral decubitus positions. ${ }^{18,27,29-31}$ One of the ways to promote the progression of the exercises is to create different levels of difficulty (without and against gravity). ${ }^{11}$ According to Kari Bo et al., ${ }^{41}$ a standing position increases pressure on the bladder and PFM, and may decrease the effectiveness of PFM contraction, affecting the reduction of muscle strength.

According to recent studies, ${ }^{42,43}$ the PFM contraction reflex to increased intra-abdominal pressure may be inherent to the mechanism of urinary continence, but coordination of the different patterns may be acquired as a learned behavior and is currently considered complementary to SEPFM, a determining factor in any PFM reeducation protocol.

The literature cites cure rates ranging from 44 to $70 \%{ }^{13,18,44}$ In our systematic review, the objective cure rate varied between $20^{28,30}$ and $75 \%,{ }^{19}$ while the subjective cure rate ranged between $23.8^{18}$ and $75 \% .^{28}$ The low cure rate can be justified by different definitions of cure using pad test $(<1 \mathrm{~g}$ or $<2 \mathrm{~g})$. On the other hand, variations in cure rates also depend on different levels of severity of SUI, ${ }^{45}$ training program duration, ${ }^{22}$ initial PFM strength ${ }^{42}$ and patient adherence to treatment. ${ }^{22,46}$

\section{Conclusion}

SEPFM combined with digital palpation, biofeedback and vaginal cones, as well as 12 -week duration training 
parameters, with ten repetitions per series and in distinct positions seemed more effective to reduce the amount of urine leakage, also providing a subjective perception of cure compared with SEPFM alone or a lack of treatment. The limited number of studies and the heterogeneity of the intervention protocols did not allow us to identify the most effective PFM training protocol.

\section{Conflict of interest}

The authors declare no conflict of interest.

\section{Resumo}

Protocolo de treino dos músculos do pavimento pélvico em mulheres com incontinência urinária de esforço: revisão sistemática

Introdução: Os exercícios de fortalecimento dos músculos do pavimento pélvico (EFMPP) são considerados a primeira intervenção no tratamento da incontinência urinária de esforço (IUE); porém, não existe evidência sobre os parâmetros de treino.

Objetivo: Identificar o protocolo e/ou os parâmetros de treino mais eficazes no tratamento da IUE feminina.

Método: A pesquisa bibliográfica foi realizada entre janeiro de 1992 e março de 2014 nas bases de dados PubMed, Cochrane Library, PEDro, Web of Science e Lilacs. Os artigos incluídos eram de língua inglesa, estudos experimentais, comparando EFMPP com tratamento placebo, usual ou sem tratamento, com idade compreendida entre 18 e 65 anos e diagnóstico de IUE. A avaliação da qualidade metodológica foi realizada por meio da escala PEDro. Resultados: Sete artigos de elevada qualidade metodológica foram incluídos na presente revisão. A amostra foi constituída por 331 mulheres, com idade média de $44,4 \pm 5,51$ anos, duração média das perdas urinárias de $64 \pm 5,66$ meses e gravidade da IUE variando entre ligeira e grave. Os programas de EFMPP eram distintos relativamente aos parâmetros de treino dos MPP. Alguns estudos incluíram treino abdominal e técnicas adjuvantes. A taxa de cura da quantidade de perda urinária variou entre 28,6 e $80 \%$, enquanto o aumento da força dos MPP variou de 15,6 a $161,7 \%$.

Conclusão: $O$ protocolo de treino mais eficaz consiste nos EFMPP por palpação digital e supervisão combinados com biofeedback e cones vaginais, incluindo os parâmetros de treino de 12 semanas de duração, dez repetições por série e em distintas posições comparados com os EFMPP isolados ou sem tratamento.
Palavras-chave: treinamento, assoalho pélvico, incontinência urinária de esforço, mulheres.

\section{References}

1. Haylen B, De Ridder D, Freeman R, Swift S, Berghmans B, Lee J, et al.; International Urogynecological Association; International Continence Society. An International Urogynecological Association (IUGA)/International Continence Society (ICS) joint report on the terminology for female pelvic floor dysfunction. Neurourol Urodyn. 2010;29(1):4-20.

2. Hunskaar S, Burgio K, Diokno A, Herzog A, Hjälmås K, Lapitan MC. Epidemiology and natural history of urinary incontinence in women. Urology. 2003; 62(4 Suppl 1):16-23.

3. Hunskaar S, Burgio K, Clark A, Lapitan MC, Nelson R, Sillen U, et al. Epidemiology of urinary and faecal incontinence and pelvic organ prolapse (POP). Health Publications Ltd; 2005.

4. Yip SK, Cardozo L. Psychological morbidity and female urinary incontinence. Best Pract Res Clin Obstet Gynaecol. 2007; 21(2):321-9.

5. Vigod SN, Stewart DE. Major depression in female urinary incontinence. Psychosomatics. 2006; 47(2):147-51.

6. Forte C. Incontinência urinária de esforço na mulher [dissertação]. Porto: Instituto de Ciências Biomédicas Abel Salazar, Universidade do Porto, Portugal; 2011.

7. Delancey JOL, Ashton-Miller JA. Pathophysiology of adult urinary incontinence. Gastroenterology. 2004; 126(1Suppl 1):S23-32.

8. Mangera A, Patel AK, Chapple CR. Pathophysiology of urinary incontinence. Surgery. 2011; 29(6):249-53.

9. Patel AK, Chapple CR. Pathophysiology of urinary incontinence. Surgery. 2008; 26(5):188-92.

10. Soltero GA, Campoy MP, Barrero CR, Medrano SE, Pérez PM, Rodríguez PA. Tratamiento rehabilitador en la incontinencia urinaria de esfuerzo femenina. Arch Españoles Urol. 2002; 55(9):1035-46.

11. Dumoulin C, Hay-Smith EJ. Pelvic floor muscle training versus no treatment, or inactive control treatments, for urinary incontinence in women. Cochrane Database Syst Rev. 2010; (1):CD005654.

12. Dumoulin C, Glazener C, Jenkinson D. Determining the optimal pelvic floor muscle training regimen for women with stress urinary incontinence. Neurourol Urodyn. 2011; 30(5):746-53.

13. Hay-Smith EJC, Herderschee R, Dumoulin C, Herbison GP. Comparisons of approaches to pelvic floor muscle training for urinary incontinence in women. Cochrane Database Syst Rev. 2011; (12):CD009508.

14. Castro RA, Arruda RM, Zanetti MR, Santos PD, Sartori MG, Girão MJ. Single-blind, randomized, controlled trial of pelvic floor muscle training, electrical stimulation, vaginal cones, and no active treatment in the management of stress urinary incontinence. Clinics. 2008; 63(4):465-72.

15. Parkkinen A, Karjalainen E, Vartiainen M, Penttinen J. Physiotherapy for female stress urinary incontinence: individual therapy at the outpatient clinic versus home-based pelvic floor training: a 5-year follow-up study. Neurourol Urodyn. 2004; 23(7):643-8.

16. Turkan A, Inci Y, Fazli D. The short-term effects of physical therapy in different intensities of urodynamic stress incontinence. Gynecol Obstet Invest. 2005; 59(1):43-8.

17. Miller J, Sampselle C, Ashton-Miller J, Hong GR, DeLancey JL. Clarification and confirmation of the Knack maneuver: the effect of volitional pelvic floor muscle contraction to preempt expected stress incontinence. Int Urogynecol J. 2008; 19(6):773-82.

18. Zanetti MRD, Castro RDA, Rotta AL, Santos PD, Sartori M, Girão MJBC. Impact of supervised physiotherapeutic pelvic floor exercises for treating female stress urinary incontinence. São Paulo Med J. 2007; 125(5):265-9.

19. Aksac B, Aki S, Karan A, Yalcin O, Isikoglu M, Eskiyurt N. Biofeedback and pelvic floor exercises for the rehabilitation of urinary stress incontinence. Gynecol Obstet Invest. 2003; 56(1):23-7.

20. Balmforth J, Cardozo LD. Trends toward less invasive treatment of female stress urinary incontinence. Urology. 2003; 62(4 Suppl 1):52-60.

21. Bø K, Talseth T, Holme I. Single blind, randomised controlled trial of pelvic floor exercises, electrical stimulation, vaginal cones, and no treatment in management of genuine stress incontinence in women. BMJ. 1999; 318(7182):487-93.

22. Dumoulin C, Lemieux MC, Bourbonnais D, Gravel D, Bravo G, Morin M. Physiotherapy for persistent postnatal stress urinary incontinence: a randomized controlled trial. Obstet Gynecol. 2004; 104(3):504-10. 
23. Moher D, Liberati A, Tetzlaff J, Altman DG; PRISMA Group. Preferred reporting items for systematic reviews and meta-analyses: the PRISMA Statement. J Clin Epidemiol. 2009; 62(10):1006-12.

24. Urrútia G, Bonfill X. Declaración PRISMA: una propuesta para mejorar la publicación de revisiones sistemáticas y metaanálisis. Med Clín. 2010; 135(11):507-11.

25. Margaliot $Z$, Chung KC. Systematic reviews: a primer for plastic surgery research. Plast Reconstruct Surg. 2007; 120(7):1834-41.

26. Costa CML. Tradução e adaptação da PEDro Scale para a cultura portuguesa: um instrumento de avaliação de ensaios clínicos em Fisioterapia [dissertação]. Lisboa: Universidade Técnica de Lisboa, Faculdade de Motricidade Humana; 2011

27. Kamel DM, Thabet AA, Tantawy SA, Radwan MM. Effect of abdominal versus pelvic floor muscle exercises in obese Egyptian women with mild stress urinary incontinence: a randomized controlled trial. Hong Kong Physiother J. 2013; 31(1):12-8.

28. Sriboonreung T, Wongtra-ngan S, Eungpinichpong W, Laopaiboon M Effectiveness of pelvic floor muscle training in incontinent women at Maharaj Nakorn Chiang Mai Hospital: a randomized controlled trial. J Med Assoc Thai. 2011; 94(1):1-7.

29. Arvonen T, Fianu-Jonasson A, Tyni-Lenné R. Effectiveness of two conservative modes of physical therapy in women with urinary stress incontinence. Neurourol Urodyn. 2001; 20(5):591-9.

30. Glavind K, Nøhr SB, Walter S. Biofeedback and physiotherapy versus physiotherapy alone in the treatment of genuine stress urinary incontinence. Int Urogynecol J Pelvic Floor Dysfunct. 1996; 7(6):339-43.

31. Felicíssimo M, Carneiro M, Saleme C, Pinto R, da Fonseca A, da Silva-Filho A. Intensive supervised versus unsupervised pelvic floor muscle training for the treatment of stress urinary incontinence: a randomized comparative trial. Int Urogynecol J. 2010; 21(7):835-40.

32. Ghoniem G, Stanford E, Kenton K, Achtari C, Goldberg R, Mascarenhas T, et al. Evaluation and outcome measures in the treatment of female urinary stress incontinence: Internationa Urogynecological Association (IUGA) guidelines for research and clinical practice. Int Urogynecol J Pelvic Floor Dysfunct. 2007; 19(1):5-33.

33. Jørgensen L, Lose G, Andersen J. One-hour pad-weighing test for objective assessment of female urinary incontinence. Am Coll Obstet Gynecol. 1987; 69(1): 39-42.

34. Sapsford R. The pelvic floor. A clinical model for function and rehabilitation. Physiotherapy. 2001; 87(12):620-30.
35. $\mathrm{B} ø \mathrm{~K}$, Herbert $\mathrm{R}$. There is not yet strong evidence that exercise regimens other than pelvic floor muscle training can reduce stress urinary incontinence in women: a systematic review. J Physiother. 2013; 59(1):159-68.

36. Neumann PB, Grimmer KA, Deenadayalan Y. Pelvic floor muscle training and adjunctive therapies for the treatment of stress urinary incontinence in women: a systematic review. BMC Womens Health. 2006; 6:11.

37. Dannecker C, Wolf V, Raab R, Hepp H, Anthuber C. EMG-biofeedback assisted pelvic floor muscle training is an effective therapy of stress urinary or mixed incontinence: a 7-year experience with 390 patients. Arch Gynecol Obstet. $2005 ; 273(2): 93-7$.

38. American College of Sports Medicine. American College of Sports Medicine position stand. Progression models in resistance training for healthy adults. Med Sci Sports Exerc. 2009; 41(3):687-708.

39. American College of Sports Medicine. American College of Sports Medicine health-related physical fitness assessment manual. Philadelphia: Lippincott Williams \& Wilkins; 2013.

40. Bø K. Pelvic floor muscle training is effective in treatment of female stress urinary incontinence, but how does it work? Int Urogynecol J Pelvic Floor Dysfunct. 2004; 15(2):76-84.

41. $\mathrm{B} ø \mathrm{~K}$, Finckenhagen B. Is there any difference in measurement of pelvic floor muscle strength in supine and standing position? Acta Obstet Gynecol Scand. 2003; 82(12):1120-4

42. Yang JM, Yang SH, Huang WC, Tzeng CR. Factors affecting reflex pelvic floor muscle contraction patterns in women with pelvic floor disorders. Ultrasound Obstet Gynecol. 2013; 42(2):224-9.

43. Dietz HP, Erdmann M, Shek KL. Reflex contraction of the levator ani in women symptomatic for pelvic floor disorders. Ultrasound Obstet Gynecol. 2012; 40(2): 215-8

44. Rett MT, Simoes JA, Herrmann V, Pinto CL, Marques AA, Morais SS. Management of stress urinary incontinence with surface electromyography-assisted biofeedback in women of reproductive age. Phys Ther. 2007; 87(2):136-42

45. Hung HC, Chih SY, Lin HH, Tsauo JY. Exercise adherence to pelvic floor muscle strengthening is not a significant predictor of symptom reduction for women with urinary incontinence. Arch Phys Med Rehabil. 2012; 93(10):1795-800

46. Konstantinidou E, Apostolidis A, Kondelidis N, Tsimtsiou Z, Hatzichristou D, Ioannides E. Short-term efficacy of group pelvic floor training under intensive supervision versus unsupervised home training for female stress urinary incontinence: a randomized pilot study. Neurourol Urodyn. $2007 ; 26(4): 486-91$ 